\title{
11 \\ THE PERFORMANCE REGIME OF PUBLIC GOVERNANCE IN TAIWAN From enhancing implementation to improving bureaucratic responsiveness ${ }^{1}$
}

\author{
Bennis Wai Yip So
}

\section{Introduction}

This chapter provides an overview of the developmental stages that have led to the application of performance-related management to government and examines performance movements in Taiwan through a critical review of the evolution of its performance regime as an institution of public governance, moving from the authoritarian era to the democratic one. This experience is compared to that of Anglophone countries. Taking advantage of and expanding on the insight from the performance regime framework offered by Colin Talbot $(2008,2010)$, this chapter explores the institutional context of performance movements in Taiwan and thereby identifies how various performance interventions were developed to steer public sector performance.

1 This study is sponsored by the Ministry of Science and Technology of Taiwan (NSC 102-2410H004-163-MY2). 
Taiwan's performance movements have their roots in the Kuomintang's rule of mainland China and paralleled those of Anglophone countries; however, Taiwan's path, agenda and institutions were unique, despite being influenced by the concurrent Anglophone development trend. The author argues that Taiwan experienced three waves of performance development, where the emphasis was initially on enhancing the capacity to implement development programs before gradually moving to building up bureaucratic responsiveness to the citizenry in public service delivery. The institutional context and its implications for the performance regime should be viewed in light of its developmentalism and paternalism. Democratisation then multiplied accountability holders and reshaped and complicated the original institutional context.

Although Western performance management models, including new public management (NPM), have diffused into Taiwan, this represents an instrumental learning intended to help the country realise its own purpose rather than simply a convergence with the Western path. Three specific shifting techniques of performance interventions, which combine local and foreign wisdom, have been identified: tracked monitoring, achievement/performance evaluation, and for-the-people service/quality management. These interventions were adopted to varying degrees in response to the aforementioned shifting emphasis on bureaucratic responsiveness.

These points are illustrated in this chapter through a historical review of the development of the Research, Development and Evaluation Commission (RDEC) - a ministry-level agency in charge of performancerelated management - and a snapshot of the performance evaluation of social welfare programs. In the following sections, a modified version of Talbot's performance regime will be first presented as an analytical framework and, subsequently, the institutional context and the performance interventions adopted in Taiwan will be examined to facilitate a comparison with the experience of Anglophone countries. 


\section{A modified version of the performance regime framework}

Studies of public sector performance are weakened if the focus is exclusively on the measurement and reporting of the performance of public organisations without considering the complicated public governance domain in which they operate. Talbot $(2008,2010)$ suggests that the unit of analysis should be expanded beyond the organisational level to encompass factors outside and around an organisation that may influence its performance. A performance regime, as an umbrella concept, has been raised to realise such a macro perspective.

Talbot's 'performance regime', as a framework, is composed of two elements: institutional context and performance interventions. Institutional context refers to the 'institutional environment' of individual public organisations, but Talbot uses the term in reference to institutional actors that steer the performance of these organisations. In the United Kingdom, apart from state institutions such as central and line ministries, the legislature and judicial bodies, these actors also consist of professional associations and user organisations (Talbot 2010:92-96). This forms a web of principal-agent relations with accountability arrangements between the actors and the public organisations, wherein the organisations must, to varying degrees and in varying ways, respond to these actors.

'Performance interventions' refers to any means and action taken by institutional actors to influence performance, including performance contracts, targets and standards. Further, taking the UK Government's approach as an example, its model of interventions contains not only top-down performance management but also market-incentive mechanisms, the participation of users, and the capability and capacity building of public organisations. These four functions are officially claimed to spur 'better public services for all' (Talbot 2010: 102).

This chapter follows this framework to examine the case in Taiwan, but the author utilises the 'institutional environment' definition of 'institutional context', which not only focuses on institutional actors and the complexity of accountability arrangements but also takes into account the state-society relationship, as well as the ideas and purposes behind performance steering. This definition is especially relevant to countries with non-democratic and non-Western settings. For instance, 
when the aim of performance steering for the United Kingdom is claimed to promote 'better public services for all', this is not necessarily the case for other countries, even when they have adopted the same instrument. Moreover, the performance movements of Anglophone countries should not be considered as a wholly static process (van Dooren et al. 2015).

\section{Institutional context: A comparison with Anglophone countries}

\section{Performance movements in Anglophone countries}

According to a historical review by van Dooren et al. (2015), ${ }^{2}$ Anglophone countries have witnessed eight performance movements since the 20th century. These movements can be clustered into three periods: 1) three between 1900 and the 1940s; 2) two in the 1950s to 1970s; 3) three in the 1980s to 2010s. They can also be grouped into two orientations: policy and management.

The emergence of the social survey movement (policy), scientific management and the science of administration (management), and cost accounting (management) in the early 20th century are identified as the earliest attempts at informing, understanding and standardising public performance. The rise of performance budgeting (management) in the postwar era further indicated the state's intention to build a mechanism of financial accountability.

The parallel effort of collecting social data for evaluating the development impact on society generated the social indicators movement (policy) in the 1960s. Fiscal hardship in the 1980s generated the well-known NPM movement (management) that subsequently spurred the evidencebased policy movement (policy) in the 1990s, which prescribes that facts and figures on outcomes rather than ideologies or opinions should inform policymaking. The latest movement was revisionism (management). It witnessed the revision of the financial and performance framework in the 2010s that further emphasised the use of performance information and tried to integrate it into accountability, budgeting and management processes.

2 An earlier version of the review can be found in van Dooren (2008). 
Despite Anglophone countries experiencing more than 100 years of development, van Dooren et al. (2015) argue that the basic ideas of performance management are stable. This point is exemplified by the case of the New York Bureau of Municipal Research (NYBMR), which was already engaged in performance measurement in the early 20th century, with many features consistent with the contemporary version (see Williams 2003). What has changed is the technological advancement that helped materialise ideas and improve measurement, as well as the increase in institutionalisation and professionalisation of performance information usage.

Another aspect of stability noted by van Dooren et al. (2015) is that the policy and management orientations coexisted rather than rotated during each period. The process of the movements, however, reflected a pendulum swing between the strategies of depoliticisation and politicisation. The first wave of the movements was to separate politics from administration (e.g. scientific management), while the movements concerning budgetary reforms demonstrated the intention of political executives to exercise control over administration. The promotion of an evidence-based policy movement appears to depoliticise policymaking (van Dooren 2008). The increasing significance of enhanced fiscal accountability as a core aim of the performance movements in Anglophone countries should also be noted.

\section{Background of Taiwan's performance movements}

Taiwan has its own storyline of performance movements, albeit under the shadow of Anglophone countries. This story can be traced back to the Kuomintang's rule in mainland China during the Second Sino-Japanese War (1937-45), when the idea of performance management was initiated and experimented with. We can see its continuance in Taiwan, where all government agencies dedicate a unit (or at least a staff member for streetlevel agencies) to address tasks concerning performance management. Since the establishment of the RDEC under the Executive Yuan (the highest authority of the state's executive branch) in 1969 (reshuffled into the National Development Council (NDC) in 2014), this function has been known as 'research and evaluation' (R\&E). Local governments duplicate this setting and all special municipalities have an RDEC for $\mathrm{R} \& \mathrm{E}$ tasks. Without an RDEC, a county-level government assigns $\mathrm{R} \& \mathrm{E}$ tasks to a staff agency, usually a planning bureau. 
The establishment of R\&E agencies/units and functions in Taiwan's governments arose from an administrative reform to enforce the idea of the administrative trinity system (ATS), coined by Chiang Kai-shek, the then supreme leader of Kuomintang and China, in 1940. This can be considered the first modern reform in China to focus on the topic of 'administration'. Why 'administration'? Because Chiang was discontented with the poor enforcement of national policies at the time. In his seminal address to present the ATS concept, titled 'Principles of administration: an outline of the administrative trinity system', on 1 December 1940, Chiang defined the principles of administration as implementing political orders (Chiang 1954: 1).

He further noted that the most serious defect in China's politics at the time was a shortage of talent to conscientiously enforce these orders (Chiang 1954: 2). In another address to a cadre training class on 6 December 1940, Chiang attributed poor performance to the absence of a well-established supervision system and the failure to develop precise and practical evaluation methods'. In addition, the problem also lay in the 'disconnection between implementation and planning'. Overall, his diagnosis was that planning, implementation and evaluation (supervision) were not well linked. The ATS aimed to effectively connect these three parts (RDEC 1989a: 5). In this regard, the ATS was policy-oriented, especially concerning the enforcement of policy or implementability that was supposed to be enhanced by using evaluation or monitoring tools. The evaluation in turn provided feedback for planning purposes.

Chiang's initiative can be considered a Chinese version of Woodrow Wilson's Study of Administration (1887). This Chinese version did not, however, call for developing a field of administration that '[lay] outside the proper sphere of politics' (Wilson 1887: 210), which later evolved into the notion of a politics-administration dichotomy. What Chiang contributed, rather, was his identification of distinct functions between politics and administration and his calling for the development of the talent of administration.

This initiative was not followed by the establishment of a politically neutral civil service. Interestingly, the then prevailing scientific management movement also appealed to Chiang, but it was promoted not only to enhance administrative efficiency but also to serve in building the nation and to establish an 'omnipotent government' (RDEC 1989a: 10, 35, 90). 
In this sense, for Chiang, an administration equipped with scientific management was only an extension of politics for the state-led purpose of development.

During the period from 1941 to 1947, two institutions were established to realise the concept of the ATS. One was the Central Planning Bureau (CPB) and the other was the Party-Government Work Evaluation Commission (PWEC). The CPB took charge of the state's general policy planning and examination of political and economic development plans of party-government agencies; the PWEC took charge of the evaluation of the performance of party-government agencies. The new institutions had a limited impact during the wartime era.

Despite the failure of the reform, prototypes for many R\&E practices advocated by Chiang in his ATS address were already sprouting and were later transplanted into Taiwan. The Rules of Evaluation of Party-Government Works, promulgated in June 1941, stipulated how an evaluation exercise for government agencies should be conducted. The evaluation involved reviewing written work reports and an annual site visit. The rules already required work reports to present statistical data that would help project the work's progress. An agency's evaluation report was expected to compare its performance with that of the previous year.

Cross-agency performance comparison was expected to be conducted for subsequent sanctions and rewards (PWEC 1941). To further realise the ATS, in 1943, all party-government agencies were required to establish a Planning and Evaluation Committee for performance management. Moreover, to enhance work efficiency and skill, agencies were encouraged to organise various job competitions (Li 1953: 202-04). The aforementioned practices appear surprisingly similar to the concept of a 'competitive government', which was advocated in one of the major NPM works, Reinventing Government (Osborne \& Gaebler 1992).

During the war, the ATS had already embraced the principles of contemporary performance management, such as in the case of the NYBMR. Its lack of impact was due to the absence of techniques and practical skills to fulfil the given principles. However, learning and transfer of knowledge was not undertaken until the Kuomintang's rule in Taiwan. 


\section{The R\&E system in Taiwan}

The CPB and the PWEC were abolished after the enforcement of the constitution of the Republic of China in 1947. The fall of the Kuomintang's rule on the mainland in 1949 further suspended the development of the ATS. The émigré regime in Taiwan relaunched the evaluation exercise in the name of 'achievement evaluation' as early as 1951, but administrative reforms were not salient in the first years of its rule on the island. Indeed, an across-the-board administrative re-engineering was not launched until the end of 1966, when Chiang ordered the Executive Yuan to carry out a thorough administrative overhaul. He further suggested that each partygovernment organ should establish a research unit to study methods of improving their management operations and of utilising monitoring and evaluation for improvement (RDEC 1989a: 179-80). Chiang's idea was later crystallised into the founding of the RDEC in March 1969 and subsequently into other $\mathrm{R} \& \mathrm{E}$ agencies or units in central and local government agencies.

The founding of this staff agency marked a new attempt to realise the ATS. The RDEC, to a large extent, combined the functions of the CPB and the PWEC. From the perspective of its institutional context, in addition to the basic principal-agent relationship between levels in the administrative hierarchy, from June 1969 the RDEC, together with the Council for Economic Planning and Development (CEPD) and the National Science Council (NSC) (both being ministry-level agencies under the Executive Yuan), formed a systemic monitoring mechanism to respectively oversee performance in three functional areas: administration, economic development, and science and technology development. The RDEC played the role of coordinator among the three oversight institutions. Moreover, the RDEC was the government's think tank, conducting research on administrative reforms and taking charge of various reforms concerning the overall performance improvement of government agencies.

The RDEC, as well as other R\&E units affiliated with various agencies, formed nodes for coordination with external accountability holders, including the Legislative Yuan (the national legislature) and the Control Yuan (the state supervision organ). The $\mathrm{R} \& \mathrm{E}$ agencies/units at various levels of government were assigned to help follow up on the concerns and issues raised by state organs and to issue timely responses (see Figure 11.1). In this regard, tracked monitoring became the first important instrument for exercising top-down implementation control. (Further details are provided in the next section.) 


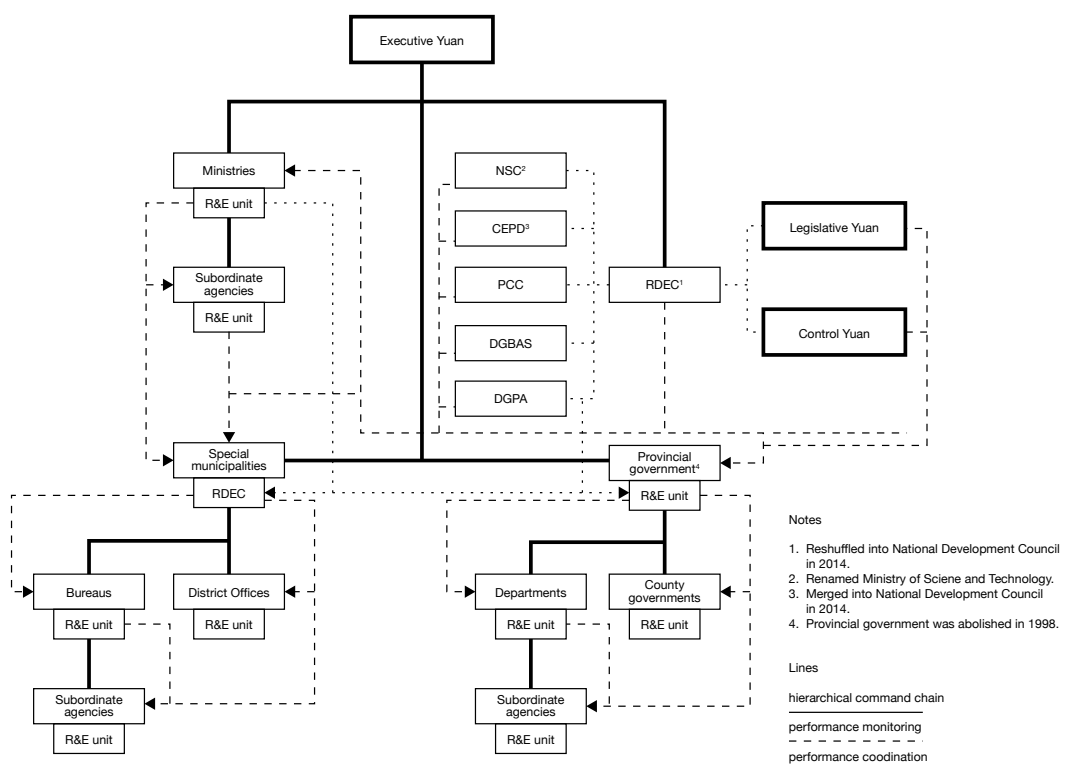

Figure 11.1. Performance regime of Taiwan

Source. Bennis Wai Yip So

With Wei Yung, a US-trained professor of political science, assuming the role of minister of the RDEC in 1976, the function of the RDEC further expanded, especially in terms of capacity building of the government. This included strengthening comprehensive and long-term policy planning and introducing computer and office automation technology to government offices. Foreign impact became increasingly manifest during his 12-year ministership. US public administration and policy science and its stateof-the-art policy research techniques (e.g. the use of opinion polls) were transferred to Taiwan. This second wave of performance movements remained policy-oriented (Wei 2004); for instance, policy implementation remained a focus point for the RDEC's research up to the early 1990s (RDEC 1994). Furthermore, under the authoritarian setting, the learning was instrumental in strengthening the state's capacity and the rationale of policymaking, even though the for-the-people service had been instigated at this stage. (Further details are provided in the next section.)

The RDEC was a powerful arm of the Executive Yuan before democratisation, directly monitoring and shaping the performance of government agencies nationwide. The Executive Yuan also assigned the RDEC ad hoc tasks to settle various public policy issues and bureaucratic 
conflicts, exemplified by its effort to help integrate scattered health insurance systems, which had been developed or overseen by various government departments, into a uniform system in the early 1990s (RDEC 1996). However, the RDEC has never extended into the financial domain to become a super ministry. Hence, its authority is somewhat different from the Office of Management and Budget (OMB) in the United States.

In general, the role of the RDEC can be compared to a 'technostructure' of the 'machine bureaucracy' under the structural configurations of Henry Mintzberg (1979). The technostructure is located between the 'strategic apex' at the top and the 'operating core' at the bottom, but it is not part of 'middle line' management and lies outside the basic flow of operating work. The technostructure serves as an analytical unit to standardise the work of other units and to apply analytical techniques that help organisations adapt to their environment.

During the democratisation process of the 1990s, in the third wave of performance movements, the RDEC's power gradually declined in parallel with ebbing authoritarianism. Workload pressures on the RDEC also entailed the concentration of its functions on key missions. The rise of local autonomy made local governments more accountable to the local people than to the central government. The RDEC thus repositioned itself as a facilitator of administrative reforms. Government agencies were required to monitor their performance with pre-existing management tools, except for those issues and policies spotlighted by the central government.

The RDEC/NDC only provided incentives to improve performance (such as offering government service awards) and started promoting the use of performance information for indicator setting. A former minister of the RDEC told the author that the RDEC/NDC is now engaged in 'coordination rather than control, service rather than tracking'. The machine bureaucracy has been transformed into a 'divisionalised form' of structure whereby the central government only designs the overall performance control system and local governments have their own technostructure to steer the performance of their agencies (Mintzberg 1979: 390). 
Furthermore, the concept of NPM diffused into Taiwan and the performance movement appeared more management-oriented. The notion of direct responsiveness to the public was introduced. The RDEC promoted a customer-oriented total quality management approach that required frontline agencies to develop diverse, tailor-made services for their communities. After the Democratic Progressive Party's (DPP) assumption of power in 2000, the government further revamped the outmoded year-end achievement evaluation into a performance evaluation by imitating the Government Performance and Results Act 1993 of the United States, associating the ex post facto evaluation with performance indicators set under an ex ante strategic plan. Performance evaluations outside the domain of the RDEC now also adopt a similar model. Despite the imitation, this wave of performance movements was less driven by fiscal restraint in Taiwan than was the case in the United States, even though performance-based budgeting was adopted (Lee \& Wang 2009). ${ }^{3}$ This can be partially explained by the fact that the RDEC/ NDC has never taken charge of or overseen a budget and finances, unlike the OMB. After two ruling-party turnovers in 2008 and 2016 and the restructuring of the Executive Yuan in the early 2010s, the basic structure of the performance regime has, to date, remained intact.

\section{Shifting techniques of performance interventions}

The emergence of the performance regime can be reviewed by considering the transformation of performance interventions. The following does not describe all the tools adopted but examines a selection of those major tools that illustrate the shifting focuses of accountability relationships and the impact of foreign developments.

\section{Tracked monitoring}

As noted earlier, tracked monitoring was the first instrument used for performance management. It contains self-developed procedures to ensure the implementation of policy programs or orders and can be compared to a form of 'process evaluation' (Weiss 1998). Any policy

3 The evaluation of budgetary performance in Taiwan mainly measures the spending ratio; it does not have any practices for cutback management or savings. 
program, public issue, official resolution (including the ruling party's during the authoritarian era) and assignment by higher up authorities, can be identified as a target for tracked monitoring. Priorities are set for various targets. Higher level R\&E agencies track key targets, while the agency-in-charge self-monitors the non-key targets and regularly reports on progress. The attainment of these targets under tracked monitoring are counted in the year-end achievement/performance evaluation. Since 2001, targets have been classified into three levels in accordance with their significance: Executive Yuan, ministry and sub-ministry. Those classified into the Executive Yuan level are tracked by the RDEC. The R\&E units affiliated with the respective ministries or the agencies-in-charge track the remainder.

Tracked monitoring is not simply a control function and was originally considered a method to facilitate the implementation of development projects. In its earliest practice, the RDEC transplanted some US enterprise management techniques, such as management by objective and program evaluation and review techniques, into the executive agencies during the process of tracked monitoring (Wei 1986: 2-3). This contributed to the Ten Major Construction Projects in the 1970s (RDEC 1980: 73-88). In addition, once a program or project encountered a bottleneck, the RDEC would be directly engaged in problem-solving and sending officers to the site to help settle problems. It was especially effective for resolving issues involving inter-agency coordination and excessive red tape. Chiang's ATS address promoted such site visits for monitoring work progress (Chiang 1954: 40).

The procedures of tracked monitoring remain in use even now; however, its positive effects and impacts have been challenged and questioned in the democratisation era due to a growing formalism that does not adequately report actual performance (Tsao 1999). Recently, frontline officials reportedly condemned the procedures as time-wasting paperwork (Yu Kai 2016).

\section{From achievement to performance evaluation}

If tracked monitoring is a process evaluation, then the achievement/ performance evaluation is an outcome evaluation. It is a year-end organisation-based evaluation that assesses the overall performance of government agencies. Its origin can be traced back to the evaluation exercise promoted during the Kuomintang's rule on the mainland. 
The version in Taiwan, originally called 'achievement evaluation', was launched in 1951 and managed by the secretariat of the Executive Yuan. The RDEC took over the exercise from its launch and conducted it in collaboration with the CEPD; the NSC; the Directorate-General of Budget, Accounting and Statistics (DGBAS) (the state organ for fiscal control); and the Directorate-General of Personnel Administration (DGPA) (the state personnel agency).

The performance scrutiny originally involved a written report and a site visit, but the site visit was only carried out once because of the time and resources that it consumed. From 1971, the evaluation exercise mainly focused on the targets of tracked monitoring (RDEC 1999a: 101-02), and a site investigation was conducted if necessary. In this early period, the assessment was descriptive and subjective. Agencies received comments on their performance but were not privy to their rating grade (Ho 1993).

In the 1990s decentralisation promoted self-monitoring of performance and the evaluation exercise only focused on the targets prioritised by the Executive Yuan. Personnel and fiscal performances were separately and respectively assessed by the DGBAS and the DGPA (RDEC 1999a). During this stage, an incentive system was introduced in which the evaluation result would incur a reward or penalty imposed on the officialsin-charge (Ho 1993).

Since the accession to power of the DPP in 2000, the evaluation has been renamed a 'performance evaluation' and it is linked with key performance indicators set by agencies, with common targets shared by all agencies, such as achieving at least the cost cutting of a service, service-standard promotion or customer satisfaction (Chang 2004). The evaluation is more quantitative and result-oriented and involves independent scholars and experts, and the evaluation report and result is disclosed to the public. This laid down a foundation of 'accountability for performance'; however, the performance information has not attracted much attention from the Legislative Yuan. Legislators do not take it into account in their budget review because the budget allocation remains a consequence of political bargaining rather than rational analysis (Chang 2013).

Despite the poor use of performance information arising from the RDEC's evaluation exercise, the practices of evaluation have diffused into other domains and have had a substantial effect. For instance, the performance evaluation of social welfare programs since 2001 has been conducted with 
a similar model and helps project a complicated institutional context under democratisation. This annual exercise to assess the performance of social welfare programs run by local governments involves a written report and a site visit. In light of the burden involved, however, since 2005, the site visit has only been carried out in alternate years.

Various central government agencies manage this evaluation, including the Ministry of Health and Welfare, DGBAS and the National Treasury Administration. For the site visit, evaluation teams are sent to each local government for one day to scrutinise their self-evaluation reports and, if necessary, to question the officer in charge. The evaluation teams are composed of officials from the central government agencies in charge of the relevant policy, as well as scholars and delegates from social welfare organisations. They examine the self-evaluation report and rate every item in accordance with given performance rating criteria. At the end of the process, the performance grades of all local governments are publicly released. Those local governments whose aggregate scores are less than 80 (full score: 100) suffer a cut in their general grant allocated by the central government.

The setting of performance indicators is not solely determined by the central government agencies. Review committees are formed for formulating the indicators for different dimensions of social welfare. All committees are composed of delegates from central government agencies, social welfare organisations and local governments, and scholars. They make adjustments to indicator settings for each exercise based on majority rule. The formulation of performance indicators resembles a participatory process, with all players able to shape the mechanism used. This results in a complicated stakeholder evaluation model that multiplies those to whom local governments are held accountable. Although local implementers can participate in the formulation of indicators, they are held accountable not only to the central government (vertically) but also to other stakeholders (horizontally).

\section{From for-the-people service to quality management}

If the ex post facto performance evaluation continues, to a large extent, responding to higher up authorities, a complementary approach to introducing the 'for-the-people service' was supposed to enhance 
responsiveness to the general public. The idea of for-the-people service was put forward by the then newly appointed premier Chiang Ching-kuo (son and successor of Chiang Kai-shek) in 1972, and it was enacted by the RDEC during the ministership of Wei Yung. A special taskforce under the RDEC was formed to hasten the service improvement of frontline agencies, especially in terms of streamlining administrative procedures (RDEC 1999b: 23-26). Note that there was no causality between the idea of for-the-people service and democracy. What Chiang wanted to promote was an ideal attitude of public servants towards the public that, he thought, should be 'like parents treating their own children with a benevolent heart' (Ministry of Civil Service 1986: 56). In this vein, we should consider it a sort of 'Chinese-style paternalism'.

Wei realised Chiang's new order by accounting for public opinion (collected from an opinion poll) through an instrument of 'system analysis', but he defined for-the-people service as 'government making use of its resources, manpower and policies to maximise the welfare for [the] majority of the people ... [through] enhancing administrative efficiency, streamlining legal and administrative procedures' (Wei 1987: 56). This seems an elite-driven 'welfare economics approach' to judging what the people's wellbeing should be.

The idea of total quality management diffused into Taiwan in the mid1990s, transforming for-the-people service into a 'program for enhancing total service quality' in 1996. The notion of customer orientation was thus introduced. Subsequently, the Service Quality Award of the Executive Yuan (1998-2007), Government Service Quality Award (2008-16), and Government Service Award (2017- ) were organised by the RDEC/NDC to encourage government agencies to actively improve their services. This practice is, to a certain extent, similar to the Beacon Scheme for local governments in the United Kingdom (Radnor 2009), which aims to disseminate best practices by encouraging applications for the award.

Different from for-the-people service, quality management now requires the participation of frontline officials in devising innovative services and directly responding to the public, whereas for-the-people services were devised by external experts, with recommendations subsequently forwarded to the agencies for adoption (RDEC 1989b: 23). 


\section{Discussion and conclusion}

At first glance, the performance movements of Anglophone countries and Taiwan are similar, especially in recent NPM-styled reforms and Taiwan's performance interventions have not gone beyond the UK Government's approach. This is not, however, simply a diffusion of the Anglophone experience into Taiwan, albeit with explicit instrumental learning and sharing of similar rhetoric. Both have worked in tandem with each other, and Taiwan has its own path, agenda and institutions.

First, the root of the movements was locally generated, and some fundamental notions behind the performance regime and means of performance interventions stem from the Kuomintang's rule in Mainland China, such as the policy-oriented ATS and the practice of performance evaluation exercises. Interestingly, certain basic ideas resemble the contemporary performance movement. This coincidence may reflect some universal principles of performance interventions.

Despite this coincidence, Taiwan's performance movements have proceeded in a unique context, in terms of a transition from an authoritarian regime to a democracy. This demonstrates the different demands of performance management that led to an alternative path to that of Anglophone countries, which sheds light on the performance regime of other transitional states, especially Communist China.

Taiwan has experienced three waves of performance movements since the founding of the RDEC. These movements gradually shifted from a policy to a management orientation. Implementation was the first concern and it underscored the state's intention to build up the function of vertical accountability through process controls during the authoritarian era. Incessant renovations of ex post facto evaluation during the first two waves of movements, albeit less significant, realised the same function as outcome evaluation, but its transformation into an NPM-styled performance evaluation after 2000 has turned it into a function of public accountability. The rise of for-the-people service during the second wave of movements marked the first attempt at building public accountability during the late authoritarian era. The third wave's encouragement of innovation in frontline service through quality management further hastened direct bureaucratic responsiveness to the public. 
In terms of the agenda, however, the movements were less fiscally driven and did not serve any purpose of depoliticisation, unlike in the Anglosphere counterparts and some Western European countries where professionalisation, in terms of developing neutral competence and professional autonomy, was a critical element (Kearney \& Sinha 1988; Farazmand 1997; Peters \& Pierre 2004). Taiwan's movements only expanded the bureaucrats' political responsiveness, with the ruling party responding directly to the public. It seems that the performance movements during the transition from authoritarianism to democracy have not passed through a process of depoliticisation.

Furthermore, Taiwan started its performance movement with the purpose of establishing an 'omnipotent government', which is a catch-up form of developmentalism engaged in by a developing country, but also a sort of state paternalism. This legacy is apparent today, even though Taiwan's democratic governments have never resurrected this symbol or slogan. State interventionism sponsored by developmentalism and paternalism has been sustained and further upheld under the enhanced legitimacy of democracy, especially as Taiwan has experienced an economic recession since the beginning of the 21 st century. ${ }^{4}$

Lastly, Taiwan established a unique performance regime, in terms of the R\&E system that sprang from the authoritarian regime and continued to evolve during democratisation. The RDEC/NDC and other R\&E units have been playing the role of performance coordinators between executive agencies, decision-making bodies and other oversight institutions. Their powerful role in monitoring and directing performance in the authoritarian era, however, has faded. Now, the R\&E system offers instruments and incentives to agencies to improve performance.

The system remains the key engine that triggers administrative reforms, even though it is less connected with the fiscal aspect. To be sure, democratisation has complicated the institutional context of the performance regime, especially with the increased engagement of various stakeholders in performance management. This phenomenon is still evolving. Further research is warranted for inquiring into its consequences.

4 Taiwan is considered to be one of East Asia's 'developmental states' in which a high degree of state interventionism spurred its economic takeoff during the authoritarian era (Wade 1990; Vartiainen 1999). Despite the growth of neoliberalism since democratisation, the state attempted to maintain the statist approach to development, despite its lack of success (Chu 2002; Wong 2006). When the thesis of illiberal democracy is applied to East Asia, some scholars argue that democratisation would not lead to the decline of state interventionism (Bell et al. 1995). 


\section{References}

Bell, DA et al. (eds) 1995, Towards Illiberal Democracy in Pacific Asia, St Martin Press, New York, doi.org/10.1057/9780230376410.

Chang, B-S 2004, 'Current situation of implementing performance evaluation of administrative agencies', in RDEC (ed), Government Performance Evaluation, Taipei, pp 175-90.

Chang, S-M 2013, A Review and Renovation of Government Performance Management System in Taiwan, RDEC-RES-101-003, Taipei.

Chiang, K-S 1954 (1940), Outline of Administrative Trinity System, Central Material Supply Center, Taipei.

Chu, Y-H 2002, 'Re-engineering the developmental state in an age of globalization: Taiwan in defiance of neo-liberalism', The China Review, vol 2, no 1, pp 29-59.

Farazmand, A 1997, 'Professionalism, bureaucracy, and modern governance: a comparative analysis', in Modern Systems of Government: Explaining the Role of Bureaucrats and Politicians, Sage, Thousand Oaks, California, pp 48-73, doi.org/10.4135/9781483327938.n2.

Ho, S-L 1993, 'Operational ideas and practices of the current achievement evaluation of administrative agencies', in RDEC (ed), Selective Collection of Administrative Performance Evaluation No. 1, Taipei, pp 1-41.

Kearney, R \& Sinha, C 1988, 'Professionalism and bureaucratic responsiveness: conflict or compatibility?', Public Administration Review, vol 48, no 1, pp 571-79, doi.org/10.2307/975521.

Lee, JY-J \& Wang, X 2009, 'Assessing the impact of performance-based budgeting: a comparative analysis across the United States, Taiwan, and China', Public Administration Review, vol 69, no s1, pp S60-S66, doi.org/10.1111/j.15406210.2009.02090.x.

Li, CH 1953, Administration Trinity System, China Local Self-Governance Association, Taipei.

Ministry of Civil Service 1986, Selective Collection of Administrative Management Essays, Ministry of Civil Service, Taipei.

Mintzberg, H 1979, The Structuring of Organizations, Prentice-Hall Inc, Englewood Cliffs, New Jersey.

Osborne, D \& Gaebler, T 1992, Reinventing Government: How the Entrepreneurial Spirit is Transforming the Public Sector, Addison-Wesley, Reading. 
Peters, BG \& Pierre, J (eds) 2004, Politicization of the Civil Service in Comparative Perspective: the Quest for Control, Routledge, London, doi.org/10.4324/ 9780203799857.

PWEC (Party-Government Work Evaluation Commission) 1941, Rules of Evaluation of Party-Government Works, Party-Government Work Evaluation Commission, Taipei.

Radnor, Z 2009, 'Understanding the relationship between a national award scheme and performance', International Review of Administrative Sciences, vol 75, no 3 pp 437-57, doi.org/10.1177/0020852309337689.

RDEC (Research, Development and Evaluation Commission) 1980, Establishment and Development of Research and Evaluation System, Taipei.

— 1989a, Selected Collection of Speeches on Administrative Management of Late President Chiang Kai-shek, Taipei.

— 1989b, The 20th Anniversaries of RDEC: A Special Issue, Taipei.

— 1994, Theory Building of Strengthening Policy Implementability, Taipei.

— 1996, Case Collection of Putting Forward the Tracked Monitoring for Exercising Control (1993-96), Taipei.

— 1999a, 30 Years of Research and Evaluation System: The 30th Anniversaries of $R D E C$, Taipei.

1999b, Establishment and Development of the R\&E System in the Government of Republic of China, Taipei.

Talbot, C 2008, 'Performance regimes - context of performance policies', International Journal of Public Administration, vol 31, pp 1569-91, doi.org/ 10.1080/01900690802199437.

— 2010, Theories of Performance: Organizational and Service Improvement in the Public Domain, Oxford University Press.

Tsao, J-H 1999, A Study of Functional Integration of Staff Agencies under the Executive Yuan, Taipei.

van Dooren, W 2008, 'Nothing new under the sun? Change and continuity in the twentieth-century performance movements', in W van Dooren \& $S$ van de Walle (ed), Performance Information in the Public Sector: How It is Used, Palgrave Macmillan, London, pp 11-23, doi.org/10.1007/978-1-13710541-7_2. 
van Dooren, W, Bouckaert, G \& Halligan, J 2015, Performance Management in the Public Sector, 2nd edn, Routledge, London.

Vartiainen, J 1999, 'The economics of successful state intervention in industrial transformation', in M Woo-Cumings (ed), The Developmental State, Cornell University Press, Ithaca, pp 200-34.

Wade, R 1990, Governing the Market: Economic Theory and the Role of Government in East Asian Industrialization, Princeton University Press, doi.org/10.1515/ 9780691187181.

Wei, Y 1986, "The current situation and the key issues of future effort of "control" and "evaluation" operation', in RDEC (ed), Collection Works of Evaluation and Assessment, Taipei, pp 1-13.

— 1987, 'Essential ideas and key points for promoting the for-the-people service', RひE Monthly, vol 11, no 6, pp 3-9.

_ 2004, Introduction to Public Policy, Wunan, Taipei.

Weiss, CH 1998, Evaluation: Methods for Studying Programs and Policies, 2nd edn, Prentice Hall, Upper Saddle River, New Jersey.

Williams, DW 2003, 'Measuring government in the early twentieth century', Public Administration Review, vol 63, no 6, pp 643-59, doi.org/10.1111/15406210.00329.

Wilson, W 1887, 'The study of administration', Political Science Quarterly, vol 2, no 2, pp 197-222, doi.org/10.2307/2139277.

Wong, J 2006, 'Technovation in Taiwan: implications for industrial governance', Governance, vol 19, no 4, pp 651-72, doi.org/10.1111/j.1468-0491.2006. 00332.x.

Yu Kai 2016, Take-Off of Rookies in the Public Sector, Locus Publishing, Taipei. 
This text is taken from Designing Governance Structures for Performance and Accountability: Developments in Australia and Greater China, edited by Andrew Podger, Tsai-tsu Su, John Wanna, Hon S. Chan and Meili Niu, published 2020 by ANU Press, The Australian National University, Canberra, Australia.

doi.org/10.22459/DGSPA.2020.11 